\title{
Molecular Abnormalities of the Glutamate Synapse in the Thalamus in Schizophrenia
}

\author{
JAMES H. MEADOR-WOODRUFF, SARAH M. CLINTON, MONICA BENEYTO, \\ AND ROBERT E. MCCULLUMSMITH \\ Mental Health Research Institute and Department of Psychiatry, \\ University of Michigan, Ann Arbor, Michigan 48109-0720, USA
}

\begin{abstract}
Schizophrenia has been associated with dysfunction of glutamatergic neurotransmission. Synaptic glutamate activates pre- and postsynaptic ionotropic NMDA, AMPA, and kainate and metabotropic receptors, is removed from the synapse via five cell surface-expressed transporters, and is packaged for release by three vesicular transporters. In addition, there is a family of intracellular molecules enriched in the postsynaptic density (PSD) that target glutamate receptors to the synaptic membrane, modulate receptor activity, and coordinate glutamate receptor-related signal transduction. Each family of PSD proteins is selective for a given glutamate receptor subtype, the most well characterized being the NMDA receptor binding proteins PSD93, PSD95, NF-L, and SAP102. Besides binding glutamate receptors, many of these proteins also interact with cell surface proteins like cell adhesion molecules, ion channels, cytoskeletal elements, and signal transduction molecules. Given the complexity of the glutamate neurotransmitter system, there are many locations where disruption of normal signaling could occur and give rise to abnormal glutamatergic neurotransmission in schizophrenia. Using multiple cohorts of postmortem tissue, we have examined these synaptic molecules in schizophrenic thalamus. The expression of NR1 and NR2C subunit transcripts is decreased in the thalamus in schizophrenia. Interestingly, three intracellular PSD molecules that link the NMDA receptor to signal transduction pathways are also abnormally expressed. Additionally, several of the cell surface and vesicular transporters are abnormal in the schizophrenic thalamus. While occasional findings of abnormal receptor expression are made, the most dramatic and consistent alterations that we have found in the thalamus in schizophrenia involve the family of intracellular signaling/scaffolding molecules. We propose that schizophrenia has a glutamatergic component that involves alterations in the intracellular machinery that is coupled to glutamate receptors, in addition to abnormalities of the receptors themselves. Our data suggest that schizophrenia is associated with abnormal glutamate receptor-related intracellular signaling in the thalamus, and point to novel targets for innovative drug discovery.
\end{abstract}

KEYWORDS: glutamate synapse; schizophrenia; phencyclidine; excitatory amino acid transporters; thalamic anatomy

Address for correspondence: James H. Meador-Woodruff, M.D., Mental Health Research Institute, Department of Psychiatry, University of Michigan, 205 Zina Pitcher Place, Ann Arbor, MI 48109-0720. Voice: 734-936-2093; fax: 734-647-4130.

jimmw@umich.edu

Ann. N.Y. Acad. Sci. 1003: 75-93 (2003). () 2003 New York Academy of Sciences. doi: 10.1196/annals.1300.005 


\section{INTRODUCTION}

Recently, increasing evidence has implicated glutamatergic abnormalities in the pathophysiology of schizophrenia. The glutamate hypothesis of schizophrenia was originally based on the observation that phencyclidine (PCP), an NMDA receptor antagonist, precipitates a schizophreniform psychosis in nonpsychiatrically ill persons. ${ }^{1-7}$ Subsequent studies have noted that the psychomimetic effects of PCP and other NMDA receptor antagonists (such as ketamine) differ markedly in their effects compared to other psychotogenic substances. For example, effects of PCP intoxication may include both positive and negative psychotic symptoms, while effects of dopamine agonists are typically limited to positive symptoms. On the basis of these clinical observations, a hypothesis of NMDA receptor hypoactivity in schizophrenia was proposed. Supporting this initial hypothesis, administration of agonists of the glycine/D-serine coagonist site of the NMDA receptor modestly attenuates psychosis, especially negative symptoms, in persons afflicted with schizophrenia. ${ }^{8-13}$ NMDA receptor activity, however, is just one component of glutamatergic neurotransmission, a tightly regulated neurotransmitter system that involves myriad other molecules. Recent efforts have focused not only on possible NMDA receptor abnormalities in schizophrenia, but also on the possibility of disturbances of other molecules associated with glutamatergic neurotransmission in this illness.

\section{GLUTAMATERGIC NEUROTRANSMISSION: A BRIEF OVERVIEW}

Glutamate neurotransmission requires three distinct cell types that comprise the typical glutamate synapse: an astrocyte, as well as both a presynaptic and a postsynaptic neuron (FIG. 1). ${ }^{14-16}$ Glutamate is packaged into secretory vesicles in the presynaptic neuron by a family of at least three vesicular transporters (vGluT1-vGluT3) and released into the synapse. ${ }^{17-21}$ Synaptic glutamate can stimulate both metabotropic and ionotropic glutamate receptors, located in receptor-specific distributions on pre- and postsynaptic neurons, as well as on astrocytes. ${ }^{14-16,22}$ Glutamate receptor subtypes (FIG. 2) include a group of pharmacologically distinct ligand-gated ion channels (NMDA, AMPA, and kainate receptors) and the eight G-protein coupled metabotropic receptors (mGluR $1-8) .{ }^{23-25}$

Glutamate is rapidly removed from the synapse by a family of at least five plasma membrane excitatory amino acid transporters (EAAT1-EAAT5), located on both synaptic neurons and astrocytes. ${ }^{16,26-34}$ Recovered glutamate may enter the TCA cycle via conversion to $\alpha$-ketoglutarate by glutamate dehydrogenase, and/or be converted to glutamine-by-glutamine synthetase and transported back into the synapse. ${ }^{14}$ One particularly interesting pathway involves reuptake of glutamine into the presynaptic neuron. Presynaptic glutamine can be oxidized to glutamate by the enzyme glutaminase and repackaged into vesicles for release. ${ }^{14}$ Glutaminase and the vesicular transporters have been proposed as markers for glutamatergic neurons. Glutaminase expression is enriched in glutamatergic neurons, and expression of the vesicular transporters appear to be exclusively in presynaptic glutamatergic terminals. ${ }^{17-21,35,36}$ The packaging, release, and reuptake of glutamate are closely regulated, since excess glutamate may lead to excitotoxic cell death and/or seizures. ${ }^{36}$ 


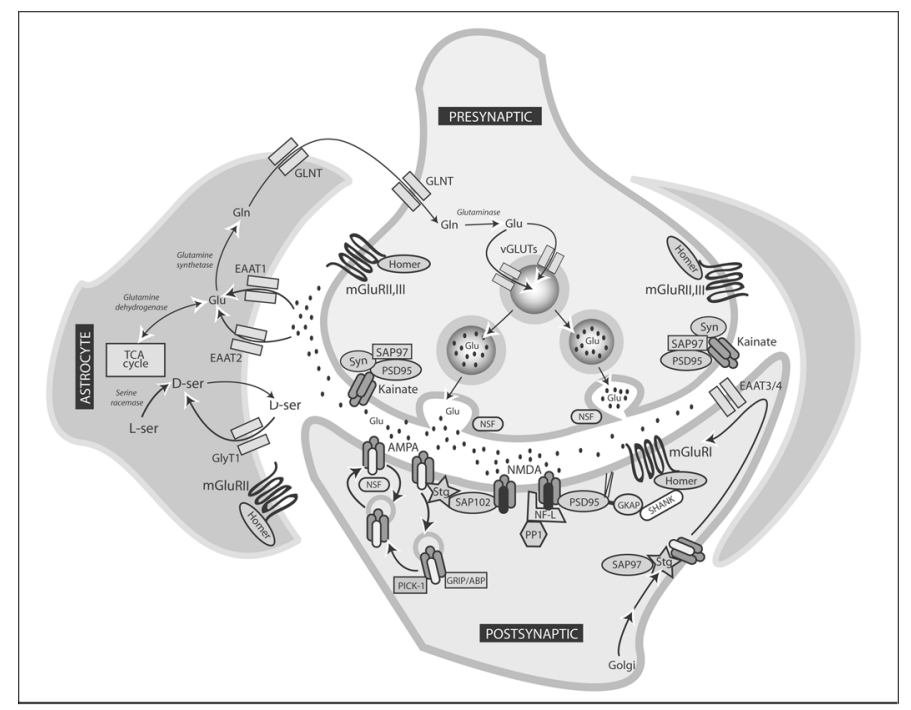

FIGURE 1. Diagram of the glutamate synapse. The glutamate synapse requires three discrete cell types: a presynaptic gluatamate-releasing neuron, a postsynaptic neuron, and an astrocyte. Glutamate is packaged into secretory vesicles by vesicular glutamate transporters. Once glutamate is released into the synapse, it can interact with a number of receptors that may exist on any of the three cell types. Each of these receptors, in turn, is associated with a series of intracellular signaling molecules that are specific for each receptor subtype. Most glutamate reuptake occurs via membrane-bound glutamate transporters located on the astrocyte, although these also exist on the postsynaptic neuron, for rapid inactivation of the actions of glutamate. Glutamate that is taken up by the astrocyte, in turn, is reduced to glutamine or alternatively enters intermediary metabolism. Glutamine is actively transported from the astrocyte back into the presynaptic neuron, where it is, in turn, oxidized to glutamate for repacking for release. In addition, astrocytes are responsible for the conversion of L-serine to D-serine, which is released by astrocytes and is an agonist of a modulatory site on the NMDA receptor complex.

Recent investigations have identified a novel group of molecules that functionally connect glutamate receptors and transporters with intracellular cytoskeletal and signaling elements. Using yeast two-hybrid techniques, families of proteins that have unique protein-protein interactions with NMDA, AMPA, kainate, and metabotropic receptors have been characterized. These intracellular proteins link these receptors to the cytoskeleton as well as to specific signal transduction pathways. Proteins that interact with the plasma membrane excitatory amino acid transporters (EAAT) have also been reported, ${ }^{37-39}$ although their function is less well characterized.

The preceding description of glutamatergic neurotransmission is brief; further details about each class of molecules are provided below when discussed in the context of abnormalities of these molecules in the thalamus in schizophrenia. 


\begin{tabular}{|c|c|c|c|c|c|c|}
\hline \multirow{3}{*}{$\begin{array}{l}\frac{\omega}{E} \\
\frac{m}{5} \\
\omega\end{array}$} & \multicolumn{6}{|c|}{ IONOTROPIC } \\
\hline & \multicolumn{2}{|c|}{ NMDA } & \multicolumn{2}{|c|}{ AMPA } & \multicolumn{2}{|c|}{ Kainate } \\
\hline & \multicolumn{2}{|c|}{$\begin{array}{l}\text { NR1 } \\
\text { NR2A-D } \\
\text { NR3A,B }\end{array}$} & \multicolumn{2}{|c|}{$\begin{array}{l}\text { GluR1 } \\
\text { GluR2 } \\
\text { GluR3 } \\
\text { GluR4 }\end{array}$} & \multicolumn{2}{|c|}{$\begin{array}{l}\text { GluR5 } \\
\text { GluR6 } \\
\text { GluR7 } \\
\text { KA1 } \\
\text { KA2 }\end{array}$} \\
\hline $\begin{array}{l}\frac{\infty}{q} \\
\frac{5}{\omega} \\
0 \\
\frac{c}{0} \\
\frac{E}{0}\end{array}$ & \multicolumn{2}{|c|}{$\begin{array}{l}\text { Glutamate } \\
\text { Glycine/D-serine } \\
\text { Polyamines } \\
\text { PCP/MK801 } \\
\text { Proton } \\
\text { Zinc ion }\end{array}$} & \multicolumn{2}{|c|}{ AMPA } & \multicolumn{2}{|c|}{ Kainate } \\
\hline \multirow[b]{2}{*}{$\begin{array}{l}\frac{2}{\bar{c}} \\
\frac{0}{0} \\
\frac{0}{2} \\
0 \\
0 \\
0\end{array}$} & Protein & subunit & Protein & Subunit & Protein & Subunit \\
\hline & $\begin{array}{l}\text { PSD95 } \\
\text { PSD93 } \\
\text { SAP102 } \\
\text { CIPP } \\
\text { Densin-180 } \\
\text { NF-L } \\
\text { Yotiao }\end{array}$ & $\begin{array}{l}\text { NR2 } \\
\text { NR2 } \\
\text { NR2 } \\
\text { NR2 } \\
\text { NR2 } \\
\text { NR1-e21 } \\
\text { NR1-e21 }\end{array}$ & $\begin{array}{l}\text { ABP } \\
\text { GRIP } \\
\text { NSF } \\
\text { PICK-1 } \\
\text { SAP97 } \\
\text { Stargazin } \\
\text { Syntenin }\end{array}$ & $\begin{array}{l}\text { GluR2/3 } \\
\text { GluR2/3 } \\
\text { GluR2/3 } \\
\text { GluR2/3,14 } \\
\text { GluR1 } \\
\text { GluR1-4 } \\
\text { GluR1-4 }\end{array}$ & $\begin{array}{l}\text { PSD95S } \\
\text { AP102 } \\
\text { SAP97 } \\
\text { PICK-1 } \\
\text { GRIP } \\
\text { Syntenin }\end{array}$ & $\begin{array}{l}\text { GluR5,6/KA2 } \\
\text { GluR6 } \\
\text { GluR6 } \\
\text { GluR5,6 } \\
\text { GluR5,6 } \\
\text { GluR5,6 }\end{array}$ \\
\hline
\end{tabular}

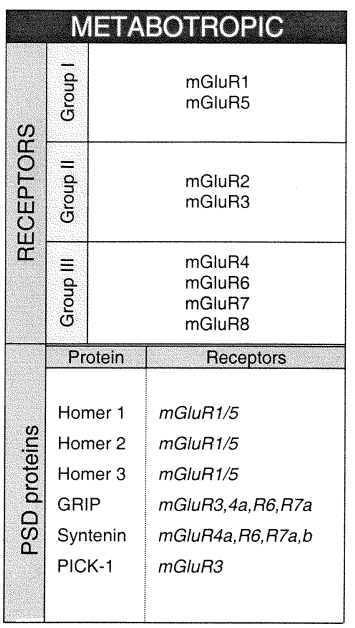

FIGURE 2. Organization of the glutamate receptors. The glutamate receptors are both ligand-gated ion channels (ionotropic), as well as seven transmembrane domain G-proteincoupled receptors (metabotropic receptors). The ionotropic receptors cluster into three definable families, the NMDA, AMPA, and kainate types. These receptors are multimeric associations of specific subunits and have specific binding domains on the final receptor complexes. The metabotropic receptors are classed into three groups, based on similar pharmacological features. In the case of both the ionotropic and the metabotropic receptors, intracellular proteins associated with the postsynaptic density have been identified that have specific associations with both types of receptors. Many of these proteins are listed in this figure with specific protein:subunit associations indicated.

\section{GLUTAMATE ABNORMALITIES IN SCHIZOPHRENIA}

We recently reviewed a number of previous studies that have examined the expression of glutamate receptors in the brain in schizophrenia that have concentrated on cortical and medial temporal lobe structures. ${ }^{40}$ These studies have generally revealed complex, region- and receptor-specific abnormalities. Several generalizations about glutamate receptor expression in the brain in schizophrenia emerge from this body of literature. First, most abnormalities have been reported in limbic cortical and hippocampal regions. Second, all three families of ionotropic glutamate receptors have been reported to be abnormal, with changes in binding sites as well as subunit changes suggestive of altered stoichiometry of subunit composition. Relatively few abnormalities have been reported for the metabotropic glutamate receptors. Finally, there are minimal to no meaningful changes in the expression of these receptors in striatal regions, indicating that abnormalities of these receptors in schizophrenia are likely region specific. 

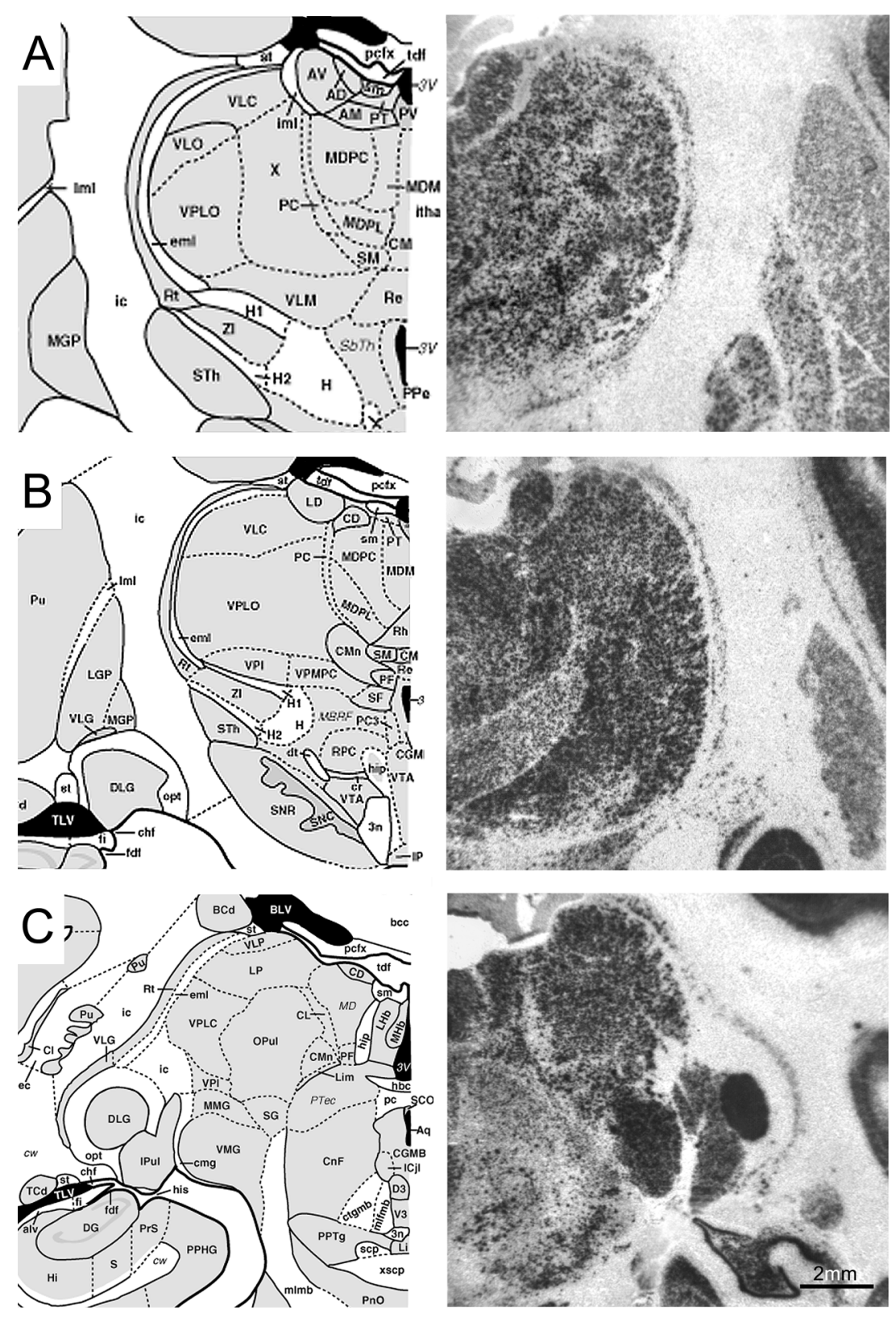

FIGURE 3. The thalamus is composed of multiple nuclei that have specific topographical projections to the neocortex, as well as to a number of subcortical structures. The left column demonstrates a schematic of these multiple nuclei at (A) a rostral level, (B) middle thalamus, and (C) more caudally. The right column shows representative in situ hybridiza- 


\section{THE THALAMUS IN SCHIZOPHRENIA}

While prefrontal and temporal cortical dysfunction is often associated with the pathophysiology of schizophrenia, recent attention has focused on the role of the thalamus in this illness. Patients with schizophrenia experience a wide range of psychotic symptoms and cognitive deficits, including hallucinations and delusions; and negative symptoms, including a relative inability to pick up on social cues and focus their attention on a particular task. ${ }^{41}$ Many of these symptoms may stem from a deficit in sensory processing. ${ }^{41-44}$ The thalamus plays a central role in processing and integrating sensory information relevant to emotional and cognitive functions, and several lines of investigation now suggest the possibility of thalamic dysfunction in the pathophysiology of schizophrenia. ${ }^{41-44}$

\section{THALAMIC ANATOMY AND CIRCUITRY}

The thalamus is composed of numerous topographically organized nuclei (FIG. 3) that project to the cortex and several subcortical regions (FIG. 4). ${ }^{45}$ Each relay nucleus receives modality-specific sensory input, such as somatosensory, visual, or auditory information, and is linked to a specific area of cerebral cortex, which processes this information and projects back to the thalamus. The thalamus is also critical for the regulation of states of consciousness, which, in turn, can influence the ability of the cortex to receive and process information. ${ }^{42}$

The thalamus contains three main cell types: excitatory relay cells, inhibitory interneurons, and the neurons of the reticular nucleus. ${ }^{46}$ Large glutamatergic relay cells in the dorsal thalamus respond to sensory afferent input, and project to the cortex, which reciprocally projects back to the thalamus. Inhibitory interneurons also located in the dorsal thalamus impinge on the dendrites of nearby relay neurons and sensory afferents. ${ }^{47}$ Neurons of the reticular nucleus reside in a thin sheet of $\gamma$-aminobutyric acid (GABA)-ergic neurons that encompass the dorsal thalamus. Reticular neurons receive excitatory input from collateral fibers of the thalamocortical and corticothalamic projections entering and leaving the dorsal thalamus. Reticular neurons, in turn, send axons into the dorsal thalamus to gate relay neuron activity. ${ }^{46,47}$ Reticular neuron activity modulates the activity of dorsal thalamic relay cells and, consequently, is able to influence the ability of the dorsal thalamus to relay sensory information to the cortex. ${ }^{42}$

Thalamic afferents and efferents primarily use either glutamate or GABA as neurotransmitters. Thalamocortical projections, as well as corticothalamic and sensory afferents to the dorsal thalamus use glutamate, which acts on both ionotropic and metabotropic glutamate receptors expressed throughout the thalamus. The intrinsic interneurons and neurons of the reticular nucleus contain GABA, and certain thalamic nuclei (anterior ventral lateral and ventral medial) receive GABAergic input from

tion images of neurofilament-light (NF-L) mRNA, which labels the preponderance of cells in the subcortical structures that are observable in these three panels. The atlas diagrams and the in situ hybridization images are from a female macaque, although the appearance of these nuclei in the human thalamus is very similar. 


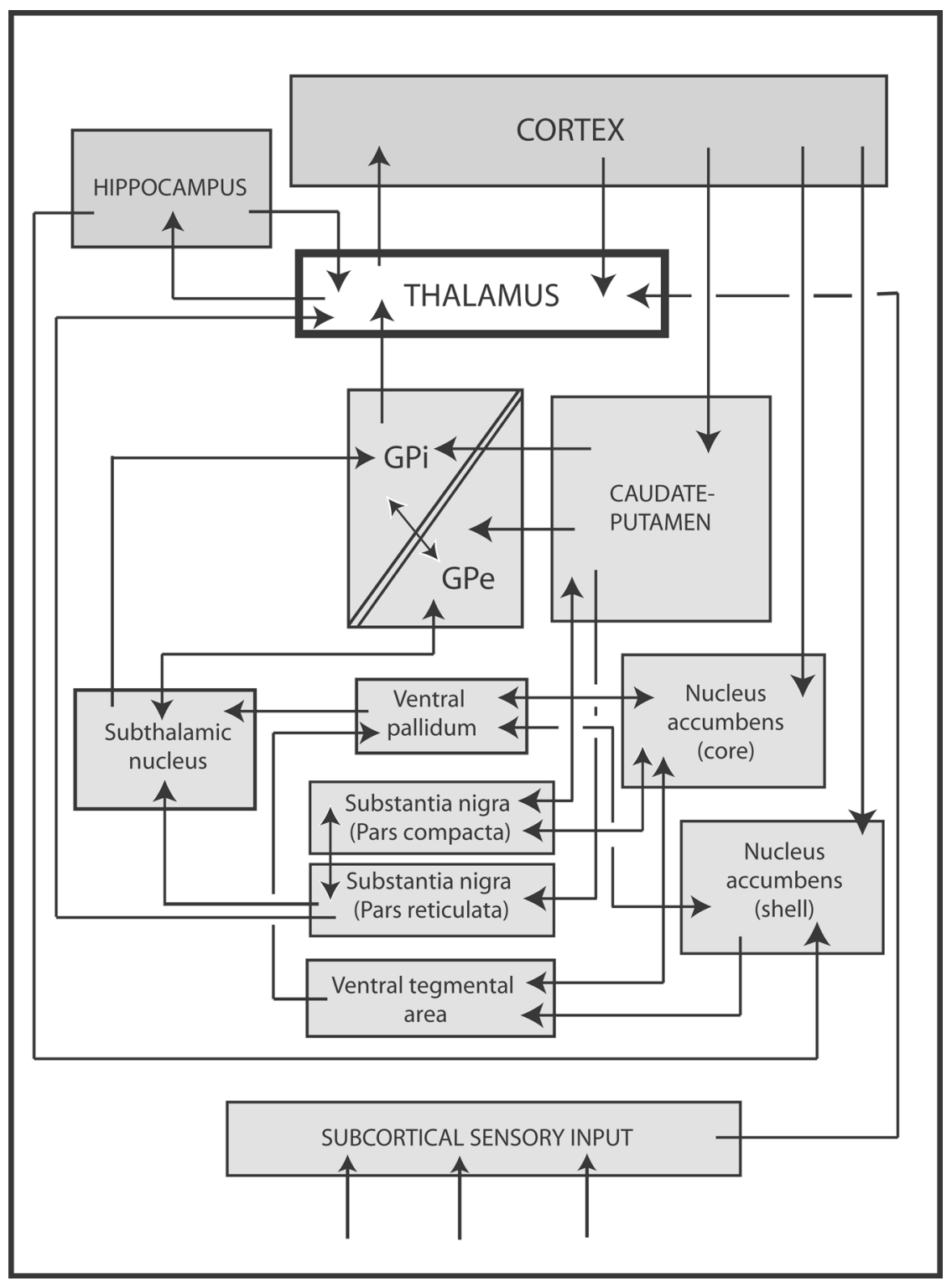

FIGURE 4. Diagram of thalamic efferents and afferents, demonstrating the central role of the thalamus in linking hippocampus, neocortex, and a number of subcortical structures. 
the internal segment of the globus pallidus, ventral pallidum, and substantia nigra pars reticulata. ${ }^{45}$ The thalamus also receives substantial noradrenergic, serotonergic, and cholinergic innervation, which likely modulates glutamatergic and GABAergic inputs. $^{46}$

\section{CELLULAR ABNORMALITIES OF THE THALAMUS IN SCHIZOPHRENIA}

Postmortem morphometric studies have reported cellular abnormalities in the thalamus in schizophrenia, particularly in the dorsomedial (DM) nucleus (FIG. 3). ${ }^{48-53}$ Using stereologic cell-counting procedures, Pakkenberg reported a $40 \%$ reduction of cell number and a $25 \%$ reduction in volume of the DM nucleus. ${ }^{48} \mathrm{~A}$ number of other studies have confirmed these findings ${ }^{50-53}$ and extended them to show that these changes are restricted to the densocellular division of the DM nucleus, which projects to the striatum and premotor cortical regions, ${ }^{51}$ and the parvocellular subdivision of the DM nucleus, which projects to dorsal and lateral areas of the prefrontal cortex. ${ }^{51,53}$ Further, another group reported decreased density of parvalbumin-immunoreactive varicosities (putative axon terminals) in middle layers of the prefrontal cortex, the primary target of DM projections. ${ }^{54}$ Cell loss in the thalamus may not be restricted to the DM nucleus. Neuron number is also reportedly decreased in the pulvinar, ${ }^{53}$ anteroventral/anteromedial, ${ }^{52}$ and ventral lateral posterior nuclei, ${ }^{55}$ but appears to be unchanged in the centromedian ${ }^{53}$ and ventral posterior medial nuclei. ${ }^{51}$

\section{VOLUMETRIC CHANGES IN THALAMUS: POSTMORTEM AND IN VIVO IMAGING STUDIES}

In addition to postmortem findings of reduced volume and cell number in certain thalamic nuclei in schizophrenia, several groups have reported reduced overall thalamic volume in schizophrenia using magnetic resonance imaging (MRI). ${ }^{56-65}$ More recent MRI studies have examined discrete thalamic nuclei and found decreased volume of the DM, ${ }^{61,66}$ pulvinar, ${ }^{66}$ central medial, anterior, and posteromedial thalamic nuclei. ${ }^{61}$ Functional brain imaging studies, using positron emission tomography (PET) and single photon emission computed tomography (SPECT), have revealed decreased thalamic metabolism in schizophrenia. ${ }^{67-74}$

\section{GLUTAMATE RECEPTOR ABNORMALITIES IN THE THALAMUS IN SCHIZOPHRENIA}

The ionotropic receptors are composed of family-specific subunits (FIG. 2). ${ }^{24}$ The AMPA receptor subunits are derived from four different genes, GluR1-GluR4 (FIG. 2). Kainate receptors are composed of subunits derived from genes for the low-affinity GluR5-GluR7 and high-affinity KA1-KA2 subunits (FIG. 2). Subunits associated with both the AMPA and kainate receptors exist in multiple forms due to alternative splicing and editing of their respective transcripts. ${ }^{24}$ Accordingly, there is the potential for heterogeneity in both AMPA and kainate receptors, based on subunit compo- 
sition and transcriptional modification of individual subunits. Subunit composition is physiologically relevant for both AMPA and kainate receptors, as unique pharmacological properties are associated with specific subunit complements in the final receptors. For example, GluR2-containing AMPA receptors have decreased calcium ion flux, which decreases the electrophysiological activity of these receptors. ${ }^{75-79}$

The NMDA receptor subunits are encoded by at least seven genes, NR1, NR2ANR2D, and NR3A-NR3B (FIg. 2). ${ }^{24,80}$ NR1 can be expressed as one of eight isoforms, due to the alternative splicing of exons 5,21 , and $22 .{ }^{24,25,81}$ The pharmacological regulation of the NMDA receptor depends upon the unique combination of binding sites. ${ }^{24}$ There is a primary site for the binding of glutamate. A separate glycine/D-serine binding site must also be occupied before glutamate can activate the ion channel. Modulatory binding sites for polyamines, $\mathrm{pH}$, and zinc have also been identified. There is a site for ionic magnesium, which blocks the ion channel at physiological concentrations. This blockade is voltage dependent; partial depolarization of the cell membrane extrudes magnesium ions. Therefore, presynaptic glutamate release and postsynaptic predepolarization are both required for NMDA receptor activity. Finally, there is a site within the ion channel itself associated with the binding of uncompetitive antagonists of the NMDA receptor, such as PCP, ketamine, and MK-801. These antagonists are use dependent, that is, the ion channel must be opened for these compounds to bind to the receptor, so there must be cooperativity between multiple sites for occupancy of uncompetitive antagonists. Similar to the AMPA and kainate receptors, subunit composition confers physiological specificity: the NMDA binding sites are associated with different subunits, and their affinities can vary depending on subunit composition. ${ }^{82-87}$

Given that the thalamus has been shown to be abnormal in schizophrenia in earlier morphometric and in vivo imaging studies, combined with the hypothesis of glutamatergic abnormalities in schizophrenia, we and others have examined the expression of glutamate receptors in the thalamus in schizophrenia. We determined the expression of the transcripts encoding all of the subunits associated with the three families of ionotropic glutamate receptors, as well as multiple binding sites associated with the NMDA, AMPA, and kainate receptors. ${ }^{88}$ In this study, we found marked decreases in the transcripts encoding both the NR1 and NR2C subunits of the NMDA receptor, particularly in limbic-associated nuclei (FIG. 5, TABLE 1).

Given that the NR1 transcript was decreased, we next determined if this decrease was associated with any specific subpopulation of NR1 isoforms. The NR1 gene contains 22 exons, and exons 5, 21, and 22 can be alternatively spliced, resulting in eight different isoforms. The $3^{\prime}$ exons 21 and 22 are particularly interesting, as it is this region of the NR1 subunit that interacts with various intracellular proteins of the postsynaptic density. In a recent study, we replicated the decreased expression of NR1 mRNA and, intriguingly, found that this reduction was exclusively associated with exon-22 containing isoforms. ${ }^{89}$

In addition, we observed decreased expression of some (but not all) of the binding sites associated with the NMDA complex: binding to both the polyamine site and the glycine/D-serine coagonist site was reduced in schizophrenia, in parallel with the decreased expression of the NR1 and NR2C subunits. We also found decreased expression of the GluR3 subunit of the AMPA receptor and the KA2 kainate receptor subunit, but both AMPA and kainate binding were preserved in schizophrenia (TABLE 1). ${ }^{88}$ 

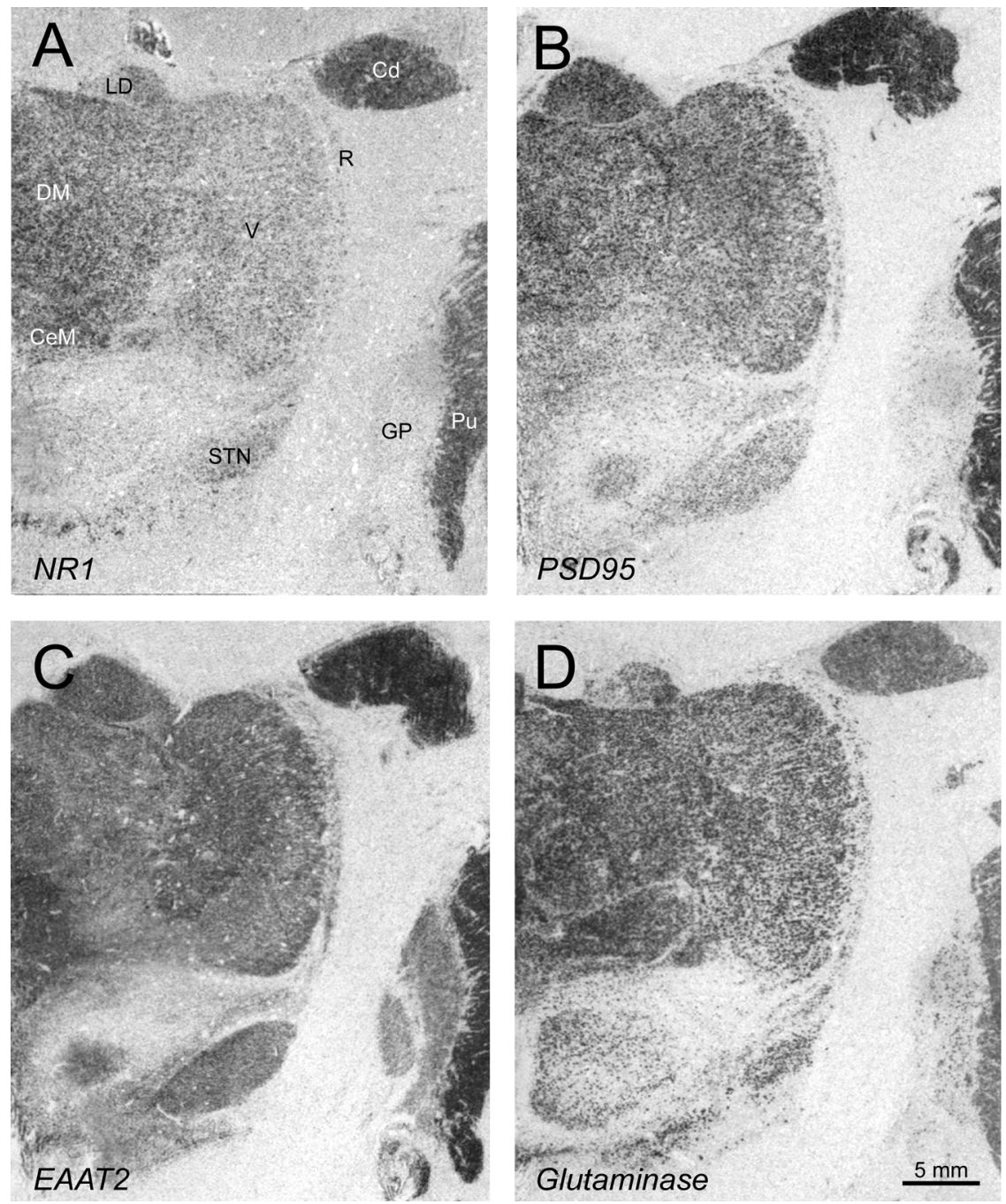

FIGURE 5. Representative in situ hybridization images of transcripts encoding key molecules associated with glutamatergic transmission. This is a section through the human thalamus at the level of the dorsomedial nucleus. (A) In situ hybridization of the NMDA subunit, NR1; (B) representative image of the intracellular signaling protein, PSD-95; (C) distribution of the transcript encoding the membrane-bound glutamate transporter, EAAT2; (D) expression of glutaminase mRNA, an enzyme localized to the presynaptic glutamate neuron responsible for the oxidation of glutamine to glutamate. Abbreviations of thalamic nuclei: $\mathrm{DM}$, dorsomedial nucleus; LD, laterodorsal nucleus; V, nuclei of the ventral tier; R, reticular nucleus; CeM, central medial nucleus. In addition, several other structures are labeled for orienting purposes: $\mathrm{Cd}$, tail of the caudate nucleus; $\mathrm{Pu}$, putamen; GP, globus pallidus; STN, subthalamic nucleus. 
TABLE 1. Glutamatergic abnormalities in the thalamus in schizophrenia

\begin{tabular}{|c|c|c|c|}
\hline & Method & Findings & Reference \\
\hline \multicolumn{4}{|l|}{ Glutamate receptors } \\
\hline Glutamate binding (NMDAR) & Autoradiography & No change & 88 \\
\hline Glycine site (NMDAR) & & Decreased & \\
\hline Polyamine site (NMDAR) & & Decreased & \\
\hline NMDA channel (MK-801) & & No change & \\
\hline AMPA receptor binding & & No change & \\
\hline Kainate receptor binding & & No change & \\
\hline NMDA NR1 & In situ hybridization & Decreased & 88 \\
\hline NMDA NR2A & & No change & \\
\hline NMDA NR2B & & Decreased & \\
\hline NMDA NR2C & & Decreased & \\
\hline NMDA NR2D & & No change & \\
\hline AMPA GluR1 & & Decreased & \\
\hline AMPA GluR2 & & No change & \\
\hline AMPA GluR3 & & Decreased & \\
\hline AMPA GluR4 & & No change & \\
\hline Kainate GluR5 & & No change & \\
\hline Kainate GluR6 & & No change & \\
\hline Kainate GluR7 & & No change & \\
\hline Kainate KA1 & & No change & \\
\hline Kainate KA2 & & Decreased & \\
\hline mGluR1 & In situ hybridization & No change & 91 \\
\hline mGluR2 & & No change & \\
\hline mGluR3 & & No change & \\
\hline mGluR4 & & No change & \\
\hline mGluR5 & & No change & \\
\hline mGluR7 & & No change & \\
\hline mGluR8 & & No change & \\
\hline NMDA NR1 & In situ hybridization & No change & 90 \\
\hline NMDA NR2A & & No change & \\
\hline AMPA GluR2 & & No change & \\
\hline AMPA GluR4 & & No change & \\
\hline Kainate GluR5 & & No change & \\
\hline Kainate GluR6 & & No change & \\
\hline \multicolumn{4}{|l|}{ Glutamate transporters } \\
\hline EAAT1 & In situ hybridization & Increased & 101 \\
\hline EAAT2 & & Increased & \\
\hline EAAT3 & & No change & \\
\hline VGLUT1 & & Not expressed & 102 \\
\hline VGLUT2 & & Increased & \\
\hline \multicolumn{4}{|l|}{ NMDAR-associated PSD proteins } \\
\hline NF-L & In situ hybridization & Increased & 89 \\
\hline PSD95 & & Increased & \\
\hline SAP102 & & Increased & \\
\hline PSD93 & & No change & \\
\hline
\end{tabular}


One other group has also examined the expression of a subset of the transcripts encoding the subunits of the ionotropic glutamate receptors in the thalamus in schizophrenia. ${ }^{90}$ In this work, transcripts encoding the NR1 and NR2A subunits of the NMDA receptors, the GluR2 and GluR4 AMPA subunits, and the kainate receptor subunit, GluR6, were measured in six patients with schizophrenia and matched controls. No changes in any of these five subunits were found in schizophrenia (TABLE 1).

In another study, we examined the expression of the transcripts encoding seven of the eight cloned metabotropic glutamate receptors in the same subjects used in our other studies in the thalamus. There were no differences in any of these receptors between the subjects with schizophrenia and the comparison group (TABLE 1). ${ }^{91}$ Together, these data indicate that there are abnormalities of glutamate receptor expression in the thalamus in schizophrenia. These abnormalities are restricted to the ionotropic receptors and particularly affect the NMDA subtype, which has changes of both subunit expression as well as binding domains for select sites on the NMDA receptor complex.

\section{NMDA-ASSOCIATED INTRACELLULAR SIGNALING PROTEINS}

When glutamate binds, the NMDA ion channel opens to permit sodium and calcium ions to enter, which, in turn, triggers multiple intracellular events. In recent years, it has become apparent that the NMDA receptor interacts with several intracellular proteins enriched in the postsynaptic density (PSD) (FIGS. 1 and 2). PSD95 and the related NR2-associated proteins, SAP102 (synapse-associated protein 102) and PSD93, contain several domains that bind the C-termini of NMDA receptor subunits, cytoskeletal proteins, and signal transduction enzymes. Through this array of protein-protein interactions, PSD95-like molecules promote NMDA receptor functions by clustering and anchoring the receptor at the PSD, modulating NMDA receptor sensitivity to glutamate and, perhaps most importantly, assembling a signaling complex to coordinate NMDA-mediated intracellular processes. ${ }^{92}$

Widespread interest in the NR2 subunit-associated PSD95 family of proteins has prompted the investigation of intracellular proteins that interact with the NR1 subunit. ${ }^{93,94}$ Two proteins, NF-L (neurofilament-light chain) ${ }^{93}$ and Yotiao, ${ }^{94}$ have been identified as proteins that interact with exon 21-containing NR1 isoforms (FIGS. 1 and 2). NF-L, along with the two other neurofilament subunits, NF-heavy and medium chains, are among the most abundant cytoskeletal elements and play an important role in the maintenance of neuronal structure. ${ }^{95} \mathrm{NF}-\mathrm{L}$ may also be involved in directing NMDA receptors to the PSD and/or linking it to the synaptic cytoskeleton. ${ }^{93,96}$ NF-L interacts with protein phosphatase-1 (PP1), a major protein/serine/ threonine phosphatase that is involved in numerous intracellular processes. ${ }^{97}$ Although the functional significance of this NF-L:PP1 interaction is not fully understood, it has been suggested that NF-L may bind PP1 and position it to dephosphorylate other PSD proteins, such as NMDA receptor subunits, or CamKII. ${ }^{98}$

Although our earlier studies showed decreased expression of NR1 and NR2C subunit transcripts, and decreased binding at the polyamine and glycine/D-serine sites of the NMDA receptor, ${ }^{88}$ we found a significant increase in the transcript expression of PSD95 and SAP102, but not PSD93 in the thalamus in schizophrenia (FIG. 5, TABLE 1). ${ }^{89}$ The total pool of PSD proteins may be increased in schizophre- 
nia in an attempt to compensate for decreased thalamic expression of NMDA receptor subunits. Enhanced expression of PSD molecules may lead to an enhanced association of the PSD proteins with the remaining NMDA subunits, an intracellular adaptation to attempt to maintain homeostasis of NMDA-related intracellular signaling in the face of decreased NMDA receptor expression, or in response to a general deficit in glutamate neurotransmission. Two other studies have examined the expression of PSD95 in schizophrenia and reported increased mRNA expression in the occipital cortex,${ }^{99}$ decreased expression in Brodmann area $9,{ }^{100}$ but no change in area 46 of the prefrontal cortex ${ }^{99}$ or hippocampus. ${ }^{100}$

We found that NF-L mRNA expression was also elevated in the thalamus in schizophrenia (TABLE 1). Although a portion of NF-L in thalamic cells may associate with the NR1 subunit to participate in NMDA function, the majority of NF-L associates with the other neurofilament subunits to maintain the neuronal cytoskeleton. It is not possible to determine if the elevated NF-L mRNA we found in schizophrenia translates into greater amounts of NF-L protein interacting with NMDA receptors, which might serve to boost an impaired glutamatergic system, or if it is part of a more general cytoskeletal response to the illness.

\section{ABNORMAL TRANSPORTER EXPRESSION}

Multiple transporters for glutamate have been identified, including families of five membrane-bound and three vesicular transporters (FIG. 1). We have expanded our examination of molecules of the glutamate synapse in schizophrenia to include these proteins. Three of the five membrane transporters are expressed in the human thalamus, EAAT1, EAAT2, and EAAT3 (FIG. 5). EAAT1 and EAAT2 are both primarily associated with astrocytes, while EAAT3 is expressed on neurons. In the same subjects used in our earlier studies in the thalamus, we determined the expression of these three transporters. ${ }^{101}$ Interestingly, both EAAT1 and EAAT2 were upregulated in schizophrenia, while EAAT3 was unchanged (TABLE 1). Both EAAT1 and EAAT2 are glial proteins, adding to a growing literature implicating glial, in addition to neuronal, abnormalities in schizophrenia.

We have also examined the expression of two of the vesicular transporters in those same subjects, vGluT1 and vGluT2 (previously identified as BNPi and DNPi, respectively). In the human thalamus, only DNPi/vGlut2 can be visualized. Similar to EAAT1 and EAAT2, the transcript encoding vGlut2 was upregulated in schizophrenia (TABLE 1). ${ }^{102}$ These data indicate that glutamatergic abnormalities in the thalamus in schizophrenia occur not only at the receptor level, but also involve both membrane and vesicular transporters. Further, these data also suggest cellular abnormalities, not only of the postsynaptic neuron (receptor abnormalities), but also of the astrocyte (EAAT1 and EAAT2) and presynaptic neuron (vGluT2) associated with transmission at the glutamatergic synapse.

Several intracellular proteins have been identified that interact with EAATs. The protein Ajuba interacts with the amino terminus of EAAT2, the intracellular protein JWA interacts with EAAT3, and the proteins KIAA0302 and ARGHEF11 both interact with EAAT4. ${ }^{37-39}$ The function of these EAAT-associated molecules has not been well characterized, but it has been proposed that they regulate the activity of the EAATs. We have recently found increased transcript expression of JWA and 
ARGHEF11 in the thalamus in schizophrenia. The functional implications of such alterations are yet to be determined.

\section{ENZYMATIC ABNORMALITIES}

Few postmortem studies have examined expression or activity of glutamatergic enzymes in schizophrenia. We have reported increased glutaminase mRNA expression (FIG. 5) in the thalamus. ${ }^{103}$ Interestingly, a fourfold increase in phosphate-activated glutaminase has been reported in the dorsolateral prefrontal cortex in schizophrenia. ${ }^{104}$ Since dorsal thalamic nuclei send projections to the dorsolateral prefrontal cortex, the increase in thalamic glutaminase transcript expression that we noted could account for some of the increase in glutaminase enzymatic activity seen in the cortex.

\section{CONCLUSIONS}

These data suggest that abnormal glutamatergic neurotransmission occurs in the thalamus in schizophrenia. Abnormalities in glutamate receptor expression (especially the NMDA receptor), intracellular signaling proteins associated with the NMDA receptor, vesicular and cell-surface transporters, intracellular proteins associated with the membrane-bound transporters, and enzymes associated with the intracellular management of glutamate as a neurotransmitter have all been reported to be abnormal in the thalamus in schizophrenia. In addition, postmortem morphometric and stereological studies, as well as in vivo imaging data implicate thalamic dysfunction in schizophrenia. Multiple PET studies have reported reduced thalamic metabolism in patients with schizophrenia, particularly when they are engaged in complex cognitive tasks. Thalamic hypoactivity is associated with cell and volume loss, especially in the MD thalamus, but also in other limbic thalamic nuclei. Taken together, these data support thalamic dysfunction in schizophrenia. It is likely that these glutamatergic, structural, and metabolic thalamic abnormalities represent a primary thalamic deficit that underlies the pathophysiology of schizophrenia, although it is possible that these changes are secondary to cortical disturbances.

\section{ACKNOWLEDGMENTS}

This work was supported by NARSAD and MH53327.

\section{REFERENCES}

1. Krystal, J.H. et al. 1994. Subanesthetic effects of the noncompetitive NMDA antagonist, ketamine, in humans. Psychotomimetic, perceptual, cognitive, and neuroendocrine responses. Arch. Gen. Psychiatry 51: 199-214.

2. JAVITT, D.C. \& S.R. ZUKIN. 1991. Recent advances in the phencyclidine model of schizophrenia. Am. J. Psychiatry 148: 1301-1308.

3. LAHTI, A.C. et al. 1995. Ketamine activates psychosis and alters limbic blood flow in schizophrenia. Neuroreport 6: 869-872. 
4. LuBy, E. et al. 1962. Model psychoses and schizophrenia. Am. J. Psychiatry 119: 61-67.

5. ITIL, T. et al. 1967. Effect of phencyclidine in chronic schizophrenics. Can. Psychiatr. Assoc. J. 12: 209-212.

6. Aanonsen, L.M. \& G.L. Wilcox. 1986. Phencyclidine selectively blocks a spinal action of N-methyl-D-aspartate in mice. Neurosci. Lett. 67: 191-197.

7. JeNTSCH, J.D. \& R.H. Roth. 1999. The neuropsychopharmacology of phencyclidine: from NMDA receptor hypofunction to the dopamine hypothesis of schizophrenia. Neuropsychopharmacology 20: 201-225.

8. Heresco-LeVy, U. et al. 2002. Placebo-controlled trial of D-cycloserine added to conventional neuroleptics, olanzapine, or risperidone in schizophrenia. Am. J. Psychiatry 159: 480-482.

9. HeRESCo-Levy, U. et al. 1998. Double-blind, placebo-controlled, crossover trial of Dcycloserine adjuvant therapy for treatment-resistant schizophrenia. Int. J. Neuropsychopharmcol. 1: 131-135.

10. Heresco-LeVY, U. et al. 1999. Efficacy of high-dose glycine in the treatment of enduring negative symptoms of schizophrenia. Arch. Gen. Psychiatry 56: 29-36.

11. Evins, A.E. et al. 2002. D-Cycloserine added to risperidone in patients with primary negative symptoms of schizophrenia. Schizophr. Res. 56: 19-23.

12. GREENE, R. et al. 2000. Short-term and long-term effects of N-methyl-D-aspartate receptor hypofunction. Arch. Gen. Psychiatry 57: 1180-1181.

13. Farber, N.B., J.W. Newcomer \& J.W. OlneY. 1999. Glycine agonists: what can they teach us about schizophrenia? Arch. Gen. Psychiatry 56: 13-17.

14. Danbolt, N.C. 2001. Glutamate uptake. Prog. Neurobiol. 65: 1-105.

15. MASSON, J. et al. 1999. Neurotransmitter transporters in the central nervous system. Pharmacol. Rev. 51: 439-464.

16. Kanai, Y., C.P. Smith \& M.A. Hediger. 1993. A new family of neurotransmitter transporters: the high-affinity glutamate transporters. FASEB J. 7: 1450-1459.

17. TAKAMORI, S. et al. 2000. Identification of a vesicular glutamate transporter that defines a glutamatergic phenotype in neurons. Nature 407: 189-194.

18. Fremeau, R.T., JR. et al. 2001. The expression of vesicular glutamate transporters defines two classes of excitatory synapse. Neuron 31: 247-260.

19. Bellocchio, E.E. et al. 2000. Uptake of glutamate into synaptic vesicles by an inorganic phosphate transporter. Science 289: 957-960.

20. Aimara, Y. et al. 2000. Molecular cloning of a novel brain-type $\mathrm{Na}(+)$-dependent inorganic phosphate cotransporter. J. Neurochem. 74: 2622-2625.

21. Bellocchio, E.E. et al. 1998. The localization of the brain-specific inorganic phosphate transporter suggests a specific presynaptic role in glutamatergic transmission. J. Neurosci. 18: 8648-8659.

22. Zhou, M. \& H.K. KimelberG. 2001. Freshly isolated hippocampal CA1 astrocytes comprise two populations differing in glutamate transporter and AMPA receptor expression. J. Neurosci. 21: 7901-7908.

23. Bleakman, D. \& D. Lodge. 1998. Neuropharmacology of AMPA and kainate receptors. Neuropharmacology 37: 1187-1204.

24. Hollmann, M. \& S. Heinemann. 1994. Cloned glutamate receptors. Annu. Rev. Neurosci. 17: 31-108.

25. NAKANISHI, S. 1992. Molecular diversity of glutamate receptors and implications for brain function. Science 258: 597-603.

26. NAGAO, S., S. KWAK \& I. KANAZAWA. 1997. EAAT4, a glutamate transporter with properties of a chloride channel, is predominantly localized in Purkinje cell dendrites, and forms parasagittal compartments in rat cerebellum. Neuroscience 78: 929-933.

27. BAR-Peled, O. et al. 1997. Distribution of glutamate transporter subtypes during human brain development. J. Neurochem. 69: 2571-2580.

28. Milton, I.D. et al. 1997. Expression of the glial glutamate transporter EAAT2 in the human CNS: an immunohistochemical study. Brain Res. Mol. Brain Res. 52: 17-31.

29. LeHre, K.P. et al. 1995. Differential expression of two glial glutamate transporters in the rat brain: quantitative and immunocytochemical observations. J. Neurosci. 15: $1835-1853$. 
30. Rothstein, J.D. et al. 1994. Localization of neuronal and glial glutamate transporters. Neuron 13: 713-725.

31. Furuta, A., J.D. Rothstein \& L.J. Martin. 1997. Glutamate transporter protein subtypes are expressed differentially during rat CNS development. J. Neurosci. 17: 8363-8375.

32. Furuta, A. et al. 1997. Cellular and synaptic localization of the neuronal glutamate transporters excitatory amino acid transporter 3 and 4. Neuroscience 81: 1031-1042.

33. YAMADA, K. et al. 1996. EAAT4 is a post-synaptic glutamate transporter at Purkinje cell synapses. Neuroreport 7: 2013-2017.

34. YamadA, K. et al. 1997. Changes in expression and distribution of the glutamate transporter EAAT4 in developing mouse Purkinje cells. Neurosci. Res. 27: 191-198.

35. LAAKE, J.H. et al. 1999. Postembedding immunogold labelling reveals subcellular localization and pathway-specific enrichment of phosphate activated glutaminase in rat cerebellum. Neuroscience 88: 1137-1151.

36. Maragakis, N.J. \& J.D. RothsteIn. 2001. Glutamate transporters in neurologic disease. Arch. Neurol. 58: 365-370.

37. MARIE, H. et al. 2002. The amino terminus of the glial glutamate transporter GLT-1 interacts with the LIM protein Ajuba. Mol. Cell. Neurosci. 19: 152-164.

38. LIN, C.I. et al. 2001. Modulation of the neuronal glutamate transporter EAAC1 by the interacting protein GTRAP3-18. Nature 410: 84-88.

39. JACKSON, M. et al. 2001. Modulation of the neuronal glutamate transporter EAAT4 by two interacting proteins. Nature 410: $89-93$.

40. Meador-Woodruff, J.M., A.J. HogG, et al. 2001. Striatal ionotropic glutamate receptor expression in schizophrenia, bipolar disorder, and major depressive disorder. Brain Res. Bull. 55(5): 631-640.

41. Andreasen, N.C., S. PARAdiso, et al. 1998. "Cognitive dysmetria" as an integrative theory of schizophrenia: a dysfunction in cortical-subcortical-cerebellar circuitry? Schizophr. Bull. 24(2): 203-218.

42. JonES, E.G. 1997. Cortical development and thalamic pathology in schizophrenia. Schizophr. Bull. 23(3): 483-501.

43. OKE, A.F. \& R.N. AdAms. 1987. Elevated thalamic dopamine: possible link to sensory dysfunctions in schizophrenia. Schizophr. Bull. 13(4): 589-604.

44. Scheibel, A.B. 1997. The thalamus and neuropsychiatric illness. J. Neuropsychiatry Clin. Neurosci. 9(3): 342-353.

45. Steriade, M., E.G. Jones, et al. 1997. Thalamus: Organization and Function. Elsevier. Amsterdam.

46. Jones, E.G. 1998. The thalamus of primates. In The Primate Nervous System, Part II. F.E. Bloom, A. Bjorklund \& T. Hokfelt, Eds.: 14: 1-246. Elsevier. New York.

47. Salt, T.E. \& S.A. Eaton. 1996. Functions of ionotropic and metabotropic glutamate receptors in sensory transmission in the mammalian thalamus. Prog. Neurobiol. 48(1): 55-72.

48. Pakkenberg, B. 1990. Pronounced reduction of total neuron number in mediodorsal thalamic nucleus and nucleus accumbens in schizophrenics. Arch. Gen. Psychiatry 47(11): 1023-1028.

49. Pakkenberg, B. 1992. The volume of the mediodorsal thalamic nucleus in treated and untreated schizophrenics. Schizophr. Res. 7(2): 95-100.

50. Pakkenberg, B. 1993. Leucotomized schizophrenics lose neurons in the mediodorsal thalamic nucleus. Neuropathol. Appl. Neurobiol. 19(5): 373-380.

51. Popken, G.J., W.E. BunneY, JR., et al. 2000. Subnucleus-specific loss of neurons in medial thalamus of schizophrenics. Proc. Natl. Acad. Sci. USA 97(16): 9276-9780.

52. Young, K., K. MANAYe, et al. 2000. Reduced number of mediodorsal and anterior thalamic neurons in schizophrenia. Biol. Psychiatry 47(11): 944-953.

53. Byne, W., M.S. Buchsbaum, et al. 2002. Postmortem assessment of thalamic nuclear volumes in subjects with schizophrenia. Am. J. Psychiatry 159(1): 59-65.

54. Lewis, D.A., D.A. CruZ, et al. 2001. Lamina-specific deficits in parvalbumin-immunoreactive varicosities in the prefrontal cortex of subjects with schizophrenia: evidence for fewer projections from the thalamus. Am. J. Psychiatry 158(9): 1411-1422.

55. Danos, P., B. BAUMANN, et al. 2002. The ventral lateral posterior nucleus of the thalamus in schizophrenia: a post-mortem study. Psychiatry Res. 114(1): 1-9. 
56. Andreasen, N.C., J.C. Ehrhardt, et al. 1990. Magnetic resonance imaging of the brain in schizophrenia. The pathophysiologic significance of structural abnormalities. Arch. Gen. Psychiatry 47(1): 35-44.

57. AndREASEn, N.C., S. ARndt, et al. 1994. Thalamic abnormalities in schizophrenia visualized through magnetic resonance image averaging. Science 266(5183): 294-298.

58. Buchsbaum, M.S. \& E.A. Hazlett. 1998. Positron emission tomography studies of abnormal glucose metabolism in schizophrenia. Schizophr. Bull. 24(3): 343-364.

59. Dasari, M., L. Friedman, et al. 1999. A magnetic resonance imaging study of thalamic area in adolescent patients with either schizophrenia or bipolar disorder as compared to healthy controls. Psychiatry Res. 91(3): 155-162.

60. Flaum, M., V.W. Swayze, 2ND, et al. 1995. Effects of diagnosis, laterality, and gender on brain morphology in schizophrenia. Am. J. Psychiatry 152(5): 704-714.

61. Gilbert, A.R., D.R. Rosenberg, et al. 2001. Thalamic volumes in patients with firstepisode schizophrenia. Am. J. Psychiatry 158(4): 618-624.

62. GUR, R.E., V. MAAnY, et al. 1998. Subcortical MRI volumes in neuroleptic-naive and treated patients with schizophrenia. Am. J. Psychiatry 155(12): 1711-1717.

63. StaAl, W.G., H.E. Hulshoff Pol, et al. 1998. Partial volume decrease of the thalamus in relatives of patients with schizophrenia. Am. J. Psychiatry 155(12): 1784-1786.

64. Ettinger, U., X.A. Chitnis, et al. 2001. Magnetic resonance imaging of the thalamus in first-episode psychosis. Am. J. Psychiatry 158(1): 116-118.

65. Konick, L.C. \& L. Friedman. 2001. Meta-analysis of thalamic size in schizophrenia. Biol. Psychiatry 49(1): 28-38.

66. Byne, W., M.S. BuchsBaum, et al. 2001. Magnetic resonance imaging of the thalamic mediodorsal nucleus and pulvinar in schizophrenia and schizotypal personality disorder. Arch. Gen. Psychiatry 58(2): 133-140.

67. Buchsbaum, M.S., T. Someya, et al. 1996. PET and MRI of the thalamus in nevermedicated patients with schizophrenia. Am. J. Psychiatry 153(2): 191-199.

68. Hazlett, E.A., M.S. Buchsbaum, et al. 1999. Three-dimensional analysis with MRI and PET of the size, shape, and function of the thalamus in the schizophrenia spectrum. Am. J. Psychiatry 156(8): 1190-1199.

69. Resnick, S.M., R.E. GuR, et al. 1988. Positron emission tomography and subcortical glucose metabolism in schizophrenia. Psychiatry Res. 24(1): 1-11.

70. TAmminga, C.A., G.K. ThaKer, et al. 1992. Limbic system abnormalities identified in schizophrenia using positron emission tomography with fluorodeoxyglucose and neocortical alterations with deficit syndrome. Arch. Gen. Psychiatry 49(7): 522-530.

71. VitA, A., S. BRESSI, et al. 1995. High-resolution SPECT study of regional cerebral blood flow in drug-free and drug-naive schizophrenic patients. Am. J. Psychiatry 152(6): 876-882.

72. AndREASEn, N.C., D.S. O'Leary, et al. 1996. Schizophrenia and cognitive dysmetria: a positron-emission tomography study of dysfunctional prefrontal-thalamic-cerebellar circuitry. Proc. Natl. Acad. Sci. USA 93(18): 9985-9990.

73. Heckers, S., S.L. Rauch, et al. 1998. Impaired recruitment of the hippocampus during conscious recollection in schizophrenia. Nat. Neurosci. 1(4): 318-323.

74. Silbersweig, D.A., E. Stern, et al. 1995. A functional neuroanatomy of hallucinations in schizophrenia. Nature 378(6553): 176-179.

75. Burnashev, N., H. Monyer, et al. 1992. Divalent ion permeability of AMPA receptor channels is dominated by the edited form of a single subunit. Neuron 8:189-198.

76. GEIGER, J.R.P., T. MELCHER, et al. 1995. Relative abundance of subunit mRNAs determines gating and $\mathrm{Ca}^{2+}$ permeability of AMPA receptors in principal neurons and interneurons in rat CNS. Neuron 15:193-204.

77. Hollmann, M., M. Hartley, et al. 1991. $\mathrm{Ca}^{2+}$ permeability of KA-AMPA-gated glutamate receptor channels depends on subunit composition. Science 252: 851-853.

78. JonAs, P., C. RACCA, et al. 1994. Differences in $\mathrm{Ca}^{2+}$ permeability of AMPA-type glutamate receptor channels in neocortical neurons caused by differential GluR-B subunit expression. Neuron 12: 1281-1289.

79. Swanson, G.T., S.K. KamboJ, et al. 1997. Single-channel properties of recombinant AMPA receptors depend on RNA editing, splice variation, and subunit composition. J. Neurosci. 17: 58-69. 
80. Andersson, O., A. Stendvist, et al. 2001. Nucleotide sequence, genomic organization, and chromosomal localization of genes encoding the human NMDA receptor subunits NR3A and NR3B. Genomics 78(3): 178-184.

81. Durand, G.M., M.V.L. Bennett, et al. 1993. Splice variants of the N-methyl-Daspartate receptor NR1 identify domains involved in regulation of polyamines and protein kinase C. Proc. Natl. Acad. Sci. USA 90: 6731-6735.

82. BoecKman, F.A. \& E. Aizenman. 1994. Stable transfection of the NMDAR1 subunit in Chinese hamster ovary cells fails to produce a functional N-methyl-D-aspartate receptor. Neurosci. Lett. 173: 189-192.

83. Gallagher, M.J., H. Huang, et al. 1996. Interactions between ifenprodil and the NR2B subunit of the N-methyl-D-aspartate receptor. J. Biol. Chem. 271: 9603-9611.

84. Grimwood, S., B. LeBourdelles, et al. 1995. Recombinant human NMDA homomeric NMDAR1 receptors expressed in mammalian cells form a high-affinity glycine antagonist binding site. J. Neurochem. 64: 525-530.

85. LyNCH, D.R., N.J. ANEGAWA, et al. 1994. N-methyl-D-Aspartate receptors: different subunit requirements for binding of glutamate antagonists, glycine antagonists, and channel-blocking agents. Mol. Pharmacol. 45: 540-545.

86. MonYer, H.R. R. SPRENGel, et al. 1992. Heteromeric NMDA receptors: molecular and functional distinction of subtypes. Science 256: 1217-1220.

87. Rodriguez-Paz, J.M., Y. Anantharam, et al. 1995. Block of the N-methyl-D-aspartate receptor by phencyclidine-like drugs is influenced by alternative splicing. Neurosci. Lett. 190: 147-150.

88. IBRAhim, H., A. HoGg, et al. 2000. Ionotropic glutamate receptor binding and subunit mRNA expression in thalamic nuclei in schizophrenia. Am. J. Psychiatry 157: 1811-1823.

89. Clinton, S.M., V. Haroutunian, et al. 2003. Altered transcript expression of NMDA receptor-associated postsynaptic proteins in the thalamus of subjects with schizophrenia. Am. J. Psychiatry 160(6): 1100-1109.

90. Popken, G.J., M.G. LegGio, et al. 2002. Expression of mRNAs related to the GABAergic and glutamatergic neurotransmitter systems in the human thalamus: normal and schizophrenic. Thalamus \& Related Systems 1: 349-369.

91. Richardson-Burns, S.M., V. Haroutunian, et al. 2000. Metabotropic glutamate receptor mRNA expression in the schizophrenic thalamus. Biol. Psychiatry 47: 22-28.

92. ShenG, M. \& D. PAK. 2000. Ligand-gated ion channel interactions with cytoskeletal and signaling proteins. Annu. Rev. Physiol. 62: 755-778.

93. EhLERS, M., E. FunG, et al. 1998. Splice variant-specific interaction of the NMDA receptor subunit NR1 with neuronal intermediate filaments. J. Neurosci. 18(2): 720-730.

94. Lin, J., M. WysZYNSKI, et al. 1998. Yotiao, a novel protein of neuromuscular junction and brain that interacts with specific splice variants of NMDA receptor subunit NR1. J. Neurosci. 18(6): 2017-2027.

95. Xu, Z., D.L. Dong, et al. 1994. Neuronal intermediate filaments: new progress on an old subject. Curr. Opin. Neurobiol. 4(5): 655-661.

96. Ehlers, M.D., W.G. Tingley, et al. 1995. Regulated subcellular distribution of the NR1 subunit of the NMDA receptor. Science 269(5231): 1734-1737.

97. Shenolikar, S. 1994. Protein serine/threonine phosphatases-new avenues for cell regulation. Annu. Rev. Cell Biol. 10: 55-86.

98. Terry-Lorenzo, R., M. InOue, et al. 2000. Neurofilament-L is a protein phosphatase-1-binding protein associated with neuronal plasma membrane and post-synaptic density. J. Biol. Chem. 275(4): 2139-2446.

99. Dracheva, S., S.A. Marras, et al. 2001. N-methyl-D-aspartic acid receptor expression in the dorsolateral prefrontal cortex of elderly patients with schizophrenia. Am. J. Psychiatry 158(9): 1400-1410.

100. Ohnuma, T., H. KATo, et al. 2000. Gene expression of PSD95 in prefrontal cortex and hippocampus in schizophrenia. NeuroReport 11(14): 3133-3137.

101. Smith, R.E., V. Haroutunian, et al. 2001. Expression of excitatory amino acid transporter transcripts in the thalamus of subjects with schizophrenia. Am. J. Psychiatry 158(9): 1393-1399.

102. Smith, R.E., V. Haroutunian, et al. 2001. Vesicular glutamate transporter transcript expression in the thalamus in schizophrenia. Neuroreport 12(13): 1-3. 
103. McCullumsmith, R.E., V. Haroutunian, et al. 2002. Expression of glutaminase transcripts in the thalamus of subjects with schizophrenia. Biol. Psychiatry 51: 25.

104. GLUCK, M.R. et al. 2002. Implications for altered glutamate and GABA metabolism in the dorsolateral prefrontal cortex of aged schizophrenic patients. Am. J. Psychiatry 159: $1165-1173$. 